\title{
Présentation des Articles
}

L'évolution politique en Amérique latine au cours de ces trente dernières années va, pour la première fois, dans le sens d'une transformation profonde de la société et des structures traditionnelles du pouvoir. Depuis 1959 deux révolutions ont réussi et se sont inscrites dans les faits (Cuba et Nicaragua), une autre a échoué (Chili) et des mouvements populaires de libération se sont établis dans de nombreux autres pays. Si l'histoire de l'Amérique latine, depuis l'aube du seizième siècle, a été façonnée par la rivalité d'hégémonies étrangères et par les intérêts des factions au pouvoir, le défi lancé par les mouvements populaires a transformé le paysage politique à jamais.

D'une part, le Nouveau Théâtre d'Amérique latine reflète ce changement et, d'autre part, ce théâtre est un produit de cette évolution. Avant tout, le Nouveau Théâtre s'interroge sur lui-même et sur le rôle qui lui est dévolu à l'intérieur de ce processus de transformation sociale et politique. Ce sont les réponses idéologiques à de telles questions qui orientent la direction que prennent les divers éléments de ce mouvement: théâtre créé et joué par et pour les communautés agricoles au Nicaragua; nouveau théâtre indigène, citadin et rural, au Mexique; théâtre de protestation sous la botte des généraux en Argentine; créations collectives, jouées par des acteurs professionnels, au Brésil et en Colombie; théâtre populaire et communautaire à Cuba. Ces diverses approches ont en commun la même volonté de travailler d'une façon symbiotique avec les hommes et les femmes qui composent la réalité sociale dans laquelle ces théâtres s'inscrivent pour formuler une analyse socio-culturelle en prise directe sur la vie et pour pratiquer une action culturelle qui s'adresse aux problèmes de la vie quotidienne.

Les articles que nous publions dans ce numéro spécial témoignent de la richesse du Nouveau Théâtre en Amérique latine et montrent bien comment un tel théâtre crée une culture parallèle et concurrente à la culture traditionnelle et dominante (articles de Frischmann sur le Mexique, de Rizk sur la Colombie, de George sur le Brésil et de Kaiser-Lenoir sur l'Argentine). Les articles sur le Nouveau Théâtre à Cuba (Weiss) et au Nicaragua (Kaiser-Lenoir) illustrent parfaitement la façon dont des méthodes innovatrices se sont adaptées aux exigences d'un nouvel ordre social. Un aspect tout particulier de ce théâtre, conséquence directe des troubles politiques, concerne les exilés, interdits de travail dans leurs propres pays, qui ont enrichi la vie théâtrale ailleurs (Pianca).

Les auteurs de nos articles étudient les rapports dialectiques entre le

Theatre Research International Vol. 14, No. 2 


\section{Theatre Research International}

Nouveau Théâtre d'Amérique latine et la culture populaire dont il est issu, ainsi qu'avec les esthétiques radicales européennes (particulièrement celles de Brecht et de Grotowski) et ils suivent l'évolution de ce phénomène unique qui, par son dynamisme même, ne cesse de se remettre en question. 